\title{
¿Ayudan los libros de texto a comprender la realidad fluvial de la ciudad?
}

\author{
Agustín Cuello Gijón \\ Fundación Nueva Cultura del Agua, Universidad de Sevilla (España) \\ Francisco F. García Pérez \\ Universidad de Sevilla (España)
}





\title{
¿Ayudan los libros de texto a comprender la realidad fluvial de la ciudad?
}

\section{Do textbooks help to understand the fluvial reality of the city?}

\author{
Agustín Cuello Gijón \\ Fundación Nueva Cultura del Agua, Universidad de Sevilla (España) \\ agustin.cuellogijon@mail.uca.es \\ Francisco F. García Pérez \\ Universidad de Sevilla (España) \\ ffgarcia@us.es
}

Fecha de recepción: 16 de octubre de 2018

Fecha de aceptación: 31 de mayo de 2019

\section{Resumen}

Se analiza el tratamiento de la idea de río y sus relaciones con la ciudad en los libros de texto de Educación Secundaria, con el fin de valorar su influencia en la comprensión de los fenómenos fluviales en entornos urbanos por los escolares. Se han revisado textos de ciencias naturales y ciencias sociales de uso frecuente en España y se han sometido a análisis de contenido mediante selección y tratamiento de unidades de información, siguiendo un sistema de categorías relacionadas con el concepto de río y su interacción con la ciudad. Se concluye que la relación ciudad-río tiene escasa presencia en los libros de texto, está marcada por el valor económico del agua, el río como amenaza y en el ahorro doméstico como único compromiso. Esta visión mercantilista, antropocéntrica y superficial no facilita el aprendizaje crítico de la realidad ni ayuda al cambio necesario en las relaciones de las ciudades con sus ríos.

Palabras clave: Ríos educativos; Libros de texto; Aprendizaje; Geografía; Educación ambiental; Ciudad fluvial.

\section{Abstract}

The treatment of the idea of river and its relations with the city is analyzed in Secondary Education textbooks, in order to assess its influence on the understanding of fluvial phenomena in urban environments by schoolchildren. Texts of natural sciences and social sciences of frequent use in Spain have been reviewed and have 
¿Ayudan los libros de texto a comprender... - A.Cuello Gijón y otros

been subjected to content analysis by selection and treatment of information units, following a system of categories related to the river concept and its interaction with the city. It is concluded that the relationship city-river has little presence in textbooks, is marked by the economic value of water, the river as a threat and in domestic savings as the only commitment. This mercantilist, anthropocentric and superficial vision does not facilitate the critical learning of reality or help the necessary change in the relationships between cities and their rivers.

Keywords: Educational rivers; Textbooks; Learning; Geography; Environmental education; Fluvial city.

\section{INTRODUCGIÓN}

Las grandes aglomeraciones urbanas del planeta, Shanghái, Karachi, Nueva York, El Cairo, etc. han nacido de los ríos, así como las mayores ciudades europeas, como Londres, París, Roma o Lisboa. En la Península Ibérica, las características climáticas y geológicas han conformado una densa red fluvial que ha estructurado históricamente el sistema de poblamiento. En España peninsular el 81\% de las capitales de provincia son ciudades fluviales ${ }^{1}$, lo que supone el $89 \%$ de la población capitalina; además la mitad de las poblaciones mayores de 20.000 habitantes viven en un río o muy próxima a él. Las morfologías urbanas de las ciudades fluviales se deben al río, que define las líneas de defensa frente a las crecidas y gran parte de las comunicaciones a través de los puentes. Con independencia de su ubicación, toda la ciudad depende del río en mayor o menor medida, ya sea para su abastecimiento, alimentación, energía, transporte o para la evacuación de residuos.

$\mathrm{Al}$ crecimiento de la ciudad le ha seguido históricamente el deterioro del río, en algunos casos hasta su aniquilación, a cambio de unos servicios nunca reconocidos (Bermúdez, De Longhi, y Gavidia, 2016). La ciudad existe gracias y a costa del río y el río debe seguir existiendo a pesar de la ciudad, lo que exige un cambio de paradigma en las relaciones entre la ciudad y el sistema fluvial, en el que la gestión del agua y los espacios fluviales, la biodiversidad, los riesgos meteorológicos y el patrimonio del río adquieran un nuevo sentido (Ollero, 2012). Para ello la ciudad debe comprender y tener conciencia de su realidad fluvial, de su dependencia. Los ríos deben ser visibles, protagonistas, para que la ciudadanía los perciba como portadores de vida y cultura, lo que contrasta notablemente con las concepciones de explotación y dominio que la mayoría de la población tiene de sus ríos y sus dinámicas (Cuello, 2018).

Comprender y tomar conciencia de la realidad fluvial debe ser el resultado de un proceso educativo que, iniciado en la escuela, se refuerza en la familia y en el contexto social. Pero, como indica García Pérez (2015), "la actual educación escolar

1 Exceptuando las capitales de provincia insulares y las ciudades autónomas de Melilla y Ceuta, hay 47 ciudades en España peninsular, de las que 38 están asentadas en riberas fluviales o en desembocaduras. 
Revista de Humanidades, 37 (2019). p. 209-234. ISSN 1130-5029

no está dando respuesta a los requerimientos que se le plantean" (p.151), pues, desde esta perspectiva y considerando que la gestión del agua es uno de los mayores desafíos sociales y ambientales de este siglo, las relaciones ciudad-río deberían formar parte importante de los contenidos de aprendizaje con el fin de capacitar a los escolares para comprender e interpretar la realidad de sus ciudades (Tidball, 2010), poder afrontar de manera crítica y creativa los problemas que esta plantea y aprovechar las oportunidades que ofrece la localización ribereña. Sin embargo el protagonismo geográfico, histórico, económico y ambiental de los ríos no se corresponde con su presencia en el ámbito educativo, lo que supone una importante debilidad en la formación de una población que vive en y de los ríos. Diferentes investigaciones realizadas en educación secundaria (Cuello, 2010; Ladrera y Prat, 2016) evidencian el desconocimiento de los alumnos sobre los ríos de su ciudad, así como dificultades para explicar procesos básicos relacionados con el agua o contextualizarlos en la actividad económica de su territorio.

En los alumnos de estos niveles persisten tópicos obsoletos acerca del papel de los ríos en la naturaleza, el uso del agua o la idoneidad de determinadas medidas de ahorro (Peñas y Masip, 2011). Los conocimientos y razonamientos que manejan adolecen de rigor y coherencia y se muestran incapaces para reconocer e interpretar el entorno fluvial próximo de forma adecuada a sus edades. Ello es aún más grave en cuanto que el conocimiento académico es, con frecuencia, la única fuente de información sobre esta cuestión y el libro de texto el principal vehículo de este conocimiento. Los conceptos sobre el agua y los ríos tratados en la escuela, así como la terminología y los valores asociados, tienen enorme importancia y trascendencia en los esquemas mentales utilizados por los escolares para explicar e interpretar la realidad (Ibarra, 2007), de ahí que un tratamiento deficiente, sesgado o superficial de estas cuestiones en los libros de texto puede favorecer una cultura fluvial inadecuada, ya superada en el ámbito científico y generadora de graves problemas socioambientales y económicos.

El conocimiento tradicional se sigue transmitiendo casi inmutable mediante los materiales escolares convencionales, sobre todo los libros de texto (García Pérez, 2015), por ello hay que considerar la existencia de errores conceptuales transmitidos por estos materiales e incorporados a la cultura escolar (Reyero et al., 2007; Henry, 2010), que coexisten con otro tipo de conocimientos de procedencia diversa y con los que el alumnado aborda el trabajo académico. Por otra parte, los libros de texto son portadores de sesgos valorativos que influyen en la conformación de modelos interpretativos de la realidad (Atienza y Van Dijk, 2010; Travé y Pozuelos, 2008), que arraigan y crecen en los escolares y se consolidan en el profesorado formando sistemas de creencias muy resistentes al cambio (Cañal et al., 2016). En el caso de los ríos estos modelos llevan a concepciones "hidráulicas" y marcadamente mercantilistas como han indicado Antoranz y Herrera en sus trabajos (2003, 2007), en línea con la percepción social tradicional, que considera a los ríos como meros recursos económicos. Creemos que el conocimiento riguroso e integrado del funcionamiento 
¿Ayudan los libros de texto a comprender... - A.Cuello Gijón y otros

fluvial favorece el desarrollo de la educación ambiental en la ciudadanía, facilitando la asunción de responsabilidades y cualificando la participación ciudadana en procesos de planificación (Tidball, 2010).

En la construcción de los modelos interpretativos que usan los jóvenes y en la cultura ciudadana, el peso de la información escolar es limitado pero muy importante (García Pérez, 2008), por ello creemos de enorme interés conocer qué tipo de conocimientos se transmiten a través de los libros de texto sobre la presencia de los ríos en la ciudad y las relaciones entre ambas realidades. Las debilidades y sesgos ideológicos señalados en otras investigaciones sobre contenidos de carácter ambiental (Ibarra, 2007; Moreno-Fernández, 2015; Bermúdez, 2016) permiten anticipar que los libros de texto pueden constituir un obstáculo para el cambio de paradigma que exigen unas nuevas relaciones entre la población y el río, por lo que es necesario plantearse la cuestión ¿ayudan los libros de texto a comprender la realidad fluvial de la ciudad? En esta línea el presente artículo resume una investigación cualitativa realizada sobre libros de texto de ciencias naturales y sociales de educación secundaria de uso frecuente en España, con el fin de conocer el tratamiento que se da a los ríos en los contextos urbanos y las relaciones entre río y ciudad.

\section{MODELO FLUVIAL DE REFERENGIA}

Analizar y valorar las relaciones río-ciudad en los libros de texto exige disponer de un modelo de referencia, entendido como objetivo de conocimiento deseable en un proceso de enseñanza aprendizaje de corte constructivista a cuya consecución deberían contribuir los libros de texto como recursos educativos. Los argumentos de este modelo plantean una determinada perspectiva sobre los ríos y sus interacciones con la ciudad, con un marcado y decidido carácter ideológico, desde la que se seleccionan y analizan los contenidos de los textos. Tres son los ámbitos que alimentan este modelo: fluvial, urbano y didáctico. Para el primero nos situamos en la Nueva Cultura del Agua (Martínez Gil, 2008; Arrojo, 2008), en cuestiones urbanas abrazamos el paradigma de la Ciudad Sostenible y la Ciudad Habitable (Worldwatch Institute, 2016; Franquesa, 2017) y en el ámbito didáctico nos alineamos con los modelos de enseñanza aprendizaje basados en la investigación de problemas socioambientales en el aula (García Pérez, 2014).

En consonancia con el protagonismo de los ríos en la organización y funcionamiento del sistema de ciudades y la necesidad de establecer cambios drásticos en la gestión y uso de los sistemas fluviales, la relación río-ciudad debe ser visible y el río debe tener presencia. Nos referimos a un río como sistema complejo y cambiante, constructor de su cuenca en base al agua y su energía, parte fundamental del ciclo del agua en todas sus fases e interrelaciones, generador de bienes económicos y también ecosistémicos, culturales y espirituales. La explotación de los ríos por las ciudades, principalmente del agua y del espacio, los han llevado a una situación de 
Revista de Humanidades, 37 (2019). p. 209-234. ISSN 1130-5029

deterioro límite que debe ser conocida y valorada desde una perspectiva integrada y sustentable, con el fin de tomar las medidas necesarias que puedan devolverles su máxima naturalidad. El aumento continuado de la demanda de agua y la ocupación del espacio fluvial son dos problemas cruciales que deben acometerse desde la reorganización de la oferta y modelos de ciudad más ajustados a las necesidades de los ríos. Este proceso de cambio exige la coordinación de las ciudades de la cuenca y de cuencas vecinas, la participación activa de la población, la mejora de la legislación a todas las escalas (en esta línea van la directivas europeas) y una estrategia educativa escolar y social que alimente todo el proceso.

El hecho urbano está unido al hecho fluvial, por lo que una ciudad fluvial debe hacer visible su río, reconocerlo como factor económico, pero también como elemento vital, patrimonial y simbólico (Estepa et al., 2011), homenajearlo y mantener o recuperar todos los elementos que le son propios, el agua, los sólidos y demás arrastres, la diversidad biológica, el espacio para la movilidad y el crecimiento, los intercambios hídricos en profundidad y laterales (Pellicer y Ollero, 2004), su capacidad evocadora y lúdica, etc. La ciudad fluvial sostenible y habitable tiene un modelo de consumo y crecimiento con mínima incidencia río arriba y río abajo, reduciendo su huella ecológica en el territorio, sobre todo la hídrica, optimizando el uso del agua y considerándola un bien limitado, no un negocio. Por ello los fenómenos de sequía e inundaciones o los embalses y trasvases deben analizarse desde una perspectiva ecosistémica, valorando diversidad de enfoques y de opciones de crecimiento urbano y económico, incluso de decrecimiento. El modelo de ciudad habitable apuesta por la recuperación estructural y funcional del río, ajusta el planeamiento a las dinámicas fluviales considerando los espacios del río como espacios públicos y aprendizaje e incorporando al paisaje urbano las riberas como elementos naturales de salud, cultura y biodiversidad. Desde el punto de vista social se provocan y favorecen los procesos de participación y toma de decisiones, así como la organización de redes de conocimiento e investigación.

Desde una perspectiva didáctica consideramos el modelo de enseñanza aprendizaje basado en la investigación de problemas socioambientales (García Pérez, 2011 y 2014) el más adecuado para construir conocimiento y desarrollar competencias en torno al sistema de relaciones río-ciudad que hemos definido como deseable. La organización de los contenidos escolares no se estructura en asignaturas sino que responde a una selección de problemas relevantes, tanto desde el punto de vista social, ambiental, como por su potencial educativo, en nuestro caso los problemas derivados de la relación ciudad-territorio, el agua y los ríos. En el desarrollo de los contenidos se utilizan los conocimientos anteriores y se elaboran otros nuevos según las necesidades para abordar los problemas seleccionados, en un proceso de indagación colaborativa en el que conceptos, procedimientos, actitudes y emociones se construyen de manera progresiva en base a una secuencia de complejidad y de profundización creciente según los avances y aprendizaje de los alumnos. Los aspectos teóricos y prácticos se entrelazan en un único discurso 
¿Ayudan los libros de texto a comprender... - A.Cuello Gijón y otros

en el que tienen cabida los debates, las divergencias, la información procedente de múltiples fuentes tradicionales y emergentes y donde el trabajo de campo sigue teniendo protagonismo. Desde este modelo se pretende capacitar al alumnado para interpretar su entorno de manera crítica y actuar en favor de la resolución de los problemas socioambientales de manera sostenible, proceso en el que el profesorado está inmerso mejorando así sus competencias profesionales.

\section{GARACTERÍSTICAS DEL LIBRO DE TEXTO}

Los libros son objeto de estudio desde múltiples puntos de vista, tanto en su faceta educativa e ideológica como formal y comercial (Travé y Pozuelos, 2008; Cañal et al., 2016), siendo especialmente fructíferos y numerosos en el campo de la didáctica de las ciencias experimentales y sociales, pero en menor medida sobre problemáticas socioambientales a caballo entre ambas disciplinas como es el caso que nos ocupa.

Los libros de texto siguen siendo los recursos educativos más utilizados (García y Martínez, 2003; Cañal et al., 2016) y configuran la práctica escolar a pesar de la irrupción de las nuevas tecnologías (Braga y Belver, 2016; Fernández y Caballero, 2017). El 81,3\% de los profesores/as reconocen emplearlos bastante o mucho y el $71,9 \%$ de los padres los consideran imprescindibles como recurso didáctico, incluso por encima de internet (Asociación Nacional de Editores de Libros y material de Enseñanza [ANELE], 2018). El profesorado manifiesta preferencia por los materiales comerciales, desestimando elaboraciones artesanas (Martínez y Rodríguez, 2010) y abandonando cierta tradición docente de confección de materiales. En el curso 2016-17 se vendieron en España 44.133.440 libros texto y otros complementarios de enseñanza no universitaria, llegando a 882 millones de euros en ventas (ANELE, 2018).

Los libros de texto son interpretaciones editoriales del currículum definido por la administración educativa, de este modo son trasmisores del currículum, "representan y materializan la cultura y el conocimiento que se consideran necesarios" (Occelli y Valeiras, 2013, p.134), con información muy codificada y cerrada, organizada y segmentada en asignaturas, que en su mayoría responden a estructuras decimonónicas (García Pérez, 2015). Los contenidos que encontramos en los textos, apuntaba Chevallard (1992), son el resultado de una serie de complejas transformaciones y reelaboraciones desde su génesis en el ámbito científico hasta convertirse en información apta para ser enseñada. Por otra parte es paradójico comprobar que "la mayor parte de los libros de texto empleados para enseñar a millones de escolares no han tenido que validar su calidad educativa" (Cañal et al., 2016, p.98).

Algunos autores (Parcerisa, 1996; Fernández, 2017) resaltan el valor del libro de texto como expresión del estado del conocimiento de las disciplinas en cada momento, aunque en el caso del conocimiento hidrológico y del tratamiento de los espacios 
Revista de Humanidades, 37 (2019). p. 209-234. ISSN 1130-5029

fluviales en la ciudad, se reiteran ideas y conceptos ya superados por la comunidad científica, sin incorporar las aportaciones recientes y necesarias para la actualización de los contenidos (Parcerisa, 1996). Otra cuestión son las imprecisiones, escaso rigor o errores que encontramos en los textos y su permanencia en los estudiantes e incluso en el profesorado (Henry, 2010; Cañal et al., 2016).

Los libros de texto suelen transmitir valoraciones sesgadas por lo que carecen de la objetividad necesaria para facilitar una enseñanza crítica y abierta. Según Atienza (2010) las representaciones e interpretaciones de los procesos expresan prejuicios, discriminaciones y estereotipos, bajo los cuales subyacen determinadas orientaciones ideológicas que perpetúan una determinada manera de ver la realidad. Travé y Pozuelos $(2008$, p.4) indican al respecto:

"El libro de texto es un producto histórico que reproduce la selección cultural de un grupo social, regula la manera de entender la ciencia y la ideología a través de la enseñanza. A través de él se introduce en el aula un discurso anónimo, ajeno a la vida, narra los acontecimientos desde el nivel experto, autorizado, sin someter sus conocimientos a crítica alguna ni controversia."

Desde este enfoque se consideran las ausencias de determinados contenidos detectadas en los textos, resultado de decisiones selectivas que priman ciertos discursos sobre otros considerados irrelevantes o inconvenientes y que, según nuestro modelo de referencia de río-ciudad, debieran ocupar un lugar destacado.

La organización de los contenidos en temas, con tiempos definidos para su desarrollo, limita la iniciativa del profesorado y la contextualización a la diversidad de situaciones que ofrece el aula o el alumnado, "sustrayendo al profesor de la responsabilidad de la reflexión y la planificación de sus tareas" (Martínez Bonafé, 2008, p.69). Desde esta perspectiva el libro es una guía que dirige el curso de la enseñanza (Fernández, 2017), supeditando con ello gran parte de los elementos curriculares al criterio editorial. Parcerisa (1996, p.35) señala al respecto:

[...] los libros de texto condicionan de manera importante el tipo de enseñanza que se realiza, ya que muchos enseñantes lo utilizan de manera cerrada, sometiéndose al currículum específico que se refleja en él, tanto en lo referente a contenidos de aprendizaje como a la manera de enseñarlos.

Las ilustraciones son elementos básicos en los textos, tanto por superficie de página ocupada como por su poder de atracción: "Las ilustraciones son elementos insustituibles, que cumplen funciones fundamentales en la estructuración e integración del conocimiento, y no pueden ser consideradas en absoluto elementos menores en relación con el texto al que acompañan" (Reyero et al., 2007, p.293). Otros estudios (Perales 2006; Link-Pérez et al., 2010) señalan importantes deficiencias en el uso de las imágenes en los textos, el predominio de la función decorativa sobre la informativa, la escasa relación con el texto, etiquetas verbales obsoletas, etc., hasta 
¿Ayudan los libros de texto a comprender... - A.Cuello Gijón y otros

el punto de dificultar la comprensión de los procesos que intentan explicar, como indican Reyero y Cardak en sus estudios sobre el ciclo del agua $(2007,2010)$. En este sentido se destaca la coherencia que debe existir entre el lenguaje verbal y el visual ya que "difícilmente se pueden desligar ambas dimensiones (formal-gráfica y semántica) y es imprescindible contemplarlas en su conjunto" (Perales, 2006, p.370).

\section{MATERIAL Y MÉTODO}

Se han revisado 49 textos de ciencias naturales y sociales de las editoriales más frecuentes, de los últimos 25 años (tabla 1), la mayoría de educación secundaria obligatoria $^{2}(82 \%)$, otros de educación primaria $(12 \%)$ y el resto de bachillerato. Un $79,6 \%$ de los textos están editados entre 2007 y 2017, periodo de vigencia de las dos últimas leyes educativas LOE (2006) y LOMCE (2013). Al tratarse de un objeto de estudio interdisciplinar, se han revisado textos de Ciencias de la Naturaleza, Geología-Biología y Geografía e Historia ${ }^{3}$, seleccionados en base a criterios de accesibilidad en el marco de técnicas no probabilísticas, concretamente la causal o accidental (Bernardo y Calderero, 2000). Este tipo de muestreo, si bien puede adolecer de debilidad, lo consideramos en este caso ampliamente representativo dada la amplitud de la muestra y la situación dominante de las editoriales utilizadas.

El estudio analiza el tratamiento que se da en los libros de texto a los ríos en los contextos urbanos, con el fin de saber en qué medida facilitan o dificultan el conocimiento de la realidad fluvial de la ciudad por parte de los escolares. Es un estudio de carácter cualitativo basado en la revisión y análisis de contenido (Bernardo, 2000; Bisquerra, 2009; Vasilachis, 2006) que en línea con otras investigaciones se detiene en los aspectos didácticos e ideológicos del contenido escolar (Occelli, 2013) así como en la propuesta de actividades (Cintas, 2000) y en la información que aportan las imágenes (Perales, 2006). Todo el proceso metodológico, así como la discusión posterior de los resultados, está mediatizado por el modelo de referencia antes expuesto, en el que se definen las relaciones ciudad-río que consideramos objetivo deseable del proceso de enseñanza aprendizaje y que se fundamenta en la Nueva Cultura del Agua, la sostenibilidad urbana y la enseñanza-aprendizaje basada en la investigación de problemas socioambientales.

No se pretende cuantificar la presencia o reiteración de aspectos fluviales en los textos sino identificar la máxima variedad y diversidad de contenidos y enfoques, con el fin de apoyar con datos empíricos la respuesta a la cuestión planteada al inicio y contrastar la hipótesis de partida que apunta a los textos escolares como obstáculos para un conocimiento crítico, riguroso y complejo de los ríos.

2 La Educación Secundaria Obligatoria (ESO) corresponde a alumnado de edades comprendidas entre 12 y 16 años, si bien este rango puede ampliarse en circunstancias especiales.

3 Los títulos de los textos corresponden a denominaciones oficiales de las asignaturas en cada nivel y según la legislación educativa a la que correspondan. 
Revista de Humanidades, 37 (2019). p. 209-234. ISSN 1130-5029

Tabla 1. Muestra: número de textos, fecha de edición, nivel educativo y ámbito de conocimientos

\begin{tabular}{|c|c|c|c|c|c|c|c|c|c|c|c|c|c|c|c|c|}
\hline & \multirow[t]{2}{*}{ Nivel } & \multirow{2}{*}{$\begin{array}{l}\text { LOGSE } \\
(1990) \\
\ldots 2002\end{array}$} & \multirow{2}{*}{$\begin{array}{l}\text { LOCE } \\
(2002) \\
2003-06\end{array}$} & \multicolumn{8}{|c|}{$\operatorname{LOE}(2006)$} & \multicolumn{4}{|c|}{ LOMCE (2013) } & \multirow[b]{2}{*}{ Total } \\
\hline & & & & 2007 & .08 & .09 & .10 & .11 & .12 & .13 & .14 & 2015 & .16 & .17 & .18 & \\
\hline \multirow{4}{*}{$\begin{array}{l}\text { Educación Primaria: } \\
\text { Conocimiento del } \\
\text { Medio }\end{array}$} & $3^{\circ}$ & 1 & & & 1 & & & & & & & & & & & \multirow{4}{*}{6} \\
\hline & $4^{\circ}$ & 1 & & & & & & & & & & & & & & \\
\hline & $5^{0}$ & & 1 & & & 1 & & & & & & & & & & \\
\hline & $6^{\circ}$ & & & & & 1 & & & & & & & & & & \\
\hline \multirow{4}{*}{$\begin{array}{l}\text { ESO: } \\
\text { Ciencias de la } \\
\text { Naturaleza }\end{array}$} & $1^{\circ}$ & 1 & & 2 & & & 2 & 2 & & & & & 1 & & & \multirow{4}{*}{19} \\
\hline & $2^{\circ}$ & 1 & & & 1 & & & & 1 & & & & & & & \\
\hline & $3^{\circ}$ & & & 1 & & & 2 & 2 & & & & 1 & 1 & & & \\
\hline & $4^{\circ}$ & & & & & & & & 1 & & & & & & & \\
\hline \multirow{4}{*}{$\begin{array}{l}\text { ESO } \\
\text { Ciencias Sociales } \\
\text { Geografía e Historia }\end{array}$} & $1^{\circ}$ & 1 & & & & & 3 & 2 & & & & & 1 & & & \multirow{4}{*}{21} \\
\hline & $2^{\circ}$ & & & & & & 1 & & 1 & & & & 1 & 1 & & \\
\hline & $3^{\circ}$ & & & 5 & & & 1 & & & & & & 1 & & & \\
\hline & $4^{\circ}$ & 1 & & & 2 & & & & & & & & & & & \\
\hline BACH.CCNN & $2^{\circ}$ & 3 & & & & & & & & & & & & & & 3 \\
\hline Totales & & 9 & 1 & 32 & & & & & & & & 7 & & & & 49 \\
\hline \multirow[t]{2}{*}{$\%$} & & $18,30 \%$ & $2 \%$ & \multicolumn{8}{|c|}{$65,30 \%$} & & & & & \multirow{2}{*}{100} \\
\hline & & \multicolumn{2}{|c|}{$20,40 \%$} & \multicolumn{12}{|c|}{$79,60 \%$} & \\
\hline
\end{tabular}

Elaboración propia

En una primera fase se realizó una revisión grosera de todos los textos para localizar en cada unidad didáctica los apartados con información de interés, lo que generó una relación inicial, amplia y heterogénea, de variables con todos los contenidos referidos al ámbito del agua, la ciudad, los problemas ambientales, el paisaje o los ecosistemas. Posteriormente se llevó a cabo la reducción y clasificación de estas variables en base a los argumentos fundamentales utilizados para construir el modelo teórico de referencia, coincidentes en gran medida con las dificultades encontradas en otras investigaciones (Antoranz y Martínez, 2003; Peñas y Masip, 2011, Ladrera y Prats 2016). Como resultado se obtuvo una relación más simplificada y operativa de variables que, a modo de categorías, sirvió finalmente para la búsqueda selectiva de la información, su codificación y análisis.

Las categorías utilizadas han sido las siguientes:

a. Conceptualización de río, elementos considerados en su definición, funciones atribuidas, caracterización física, biológica y social.

b. Relaciones río-ciudad:

b.a. Río como factor de localización urbana, como fuente de recursos, visibilidad del río en la ciudad y su relación mutua. 
¿Ayudan los libros de texto a comprender... - A.Cuello Gijón y otros

b.b. Evolución histórica de la relación río-ciudad. Cambios en la morfología urbana.

b.c. Impacto ambiental del funcionamiento urbano sobre los sistemas fluviales, huella hídrica en el territorio.

b.d. Un "problema" especial: crecidas e inundaciones.

c. Actividades y/o técnicas de trabajo que facilitan la enseñanza y aprendizaje de conceptos, procedimientos o valores.

Definidas las categorías se elaboró una ficha para cada libro de texto con datos de codificación, título, año de edición, nivel, área, editorial y un número de celdillas equivalentes al de categorías para organizar las unidades de información (Bisquerra, 2009). Posteriormente se llevó a cabo una segunda lectura de detalle para la localización, selección y extracción de fragmentos de texto y también de imágenes, que constituirán las unidades para su análisis, fragmentos de información relevantes y relacionados con alguna de las categorías anteriores o con varias de ellas, que se ordenaron en las fichas de cada texto elaboradas al efecto. Por último se hizo un agrupamiento de estas unidades por categorías según la estructura ya indicada, con su código y número de página, facilitando su localización por textos, por años o por categorías (como se recoge en el Anexo I). Además de fragmentos de texto literales e imágenes, también se han considerado unidades de información las ideas centrales de textos más extensos de contenido relevante.

Las imágenes han tenido un papel destacado en el estudio, tanto desde el punto de vista cuantitativo como cualitativo, ya que aportan abundante información sobre el conocimiento que se quiere transmitir y las estrategias gráficas para lograrlo (Perales, 2006; Link-Pérez, 2010). Las imágenes se han considerado unidades de información independientes o unidas al texto cuando ambos forman un único mensaje. Para su localización y tratamiento se han digitalizado y almacenado con el mismo código asignado automáticamente por la aplicación fotográfica.

Otro aspecto a tener en cuenta han sido los contenidos o informaciones ausentes en los textos y que consideramos relevantes desde el modelo teórico de referencia y por tanto de interés para conformar un sistema de ideas deseable sobre los ríos en la ciudad. Su discusión se ha incorporado al apartado correspondiente y a las conclusiones, al constituir valoraciones de cierta subjetividad.

\section{RESULTADOS}

La revisión de los textos en base a las categorías descritas ha aportado unidades de información de diferentes características:

- Referencias textuales explícitas a alguna de las categorías, incluyendo términos definitorios de cada una de ellas como río, inundación, agua como 
Revista de Humanidades, 37 (2019). p. 209-234. ISSN 1130-5029

recurso, asentamiento en ribera, planificación hidrológica, etc.

- Asociación de texto e imágenes con referencias explícitas a alguna categoría.

- Imágenes aisladas con o sin etiqueta verbal o pies de texto complementario.

- Notas elaboradas en base a mensajes implícitos, ideas centrales o síntesis de textos extensos que desarrollan informaciones diversas alusivas a las categorías.

Se han obtenido 283 unidades de información (tabla 2) de las que 111 son ilustraciones, ya sea asociadas a texto o de forma independiente. Los libros que han aportado más información han sido de Geografía e Historia de $1^{\circ}$ con el $35 \%$ de las unidades, seguido de Geografía de $3^{\circ}$ con el $22,6 \%$ y Biología de $3^{\circ}$ con el $10,6 \%$. En conjunto, el área de ciencias sociales aporta el 73,5\% de las unidades de información, siendo similar el número de libros de las áreas social y natural.

La definición de río acompaña a los escolares de forma intermitente y reiterada durante toda la enseñanza obligatoria, tanto en ciencias naturales como en ciencias sociales, principalmente en $1^{\circ}$ y $3^{\circ}$ de educación secundaria, donde se han obtenido 21 unidades de información. Al coincidir en áreas diferentes y en el mismo curso, un alumno puede trabajar simultáneamente este concepto en clases distintas. La definición de río se trata en contextos diversos, aparece como protagonista del paisaje, como reservorio de agua en el ciclo del agua y parte de la hidrosfera al inicio de la educación secundaria, y como agente geológico al final de este ciclo educativo. Son, pues, los ámbitos geográfico y más tarde geológico (concretamente geomorfológico) los que acogen la definición de río, generalmente con cuatro características básicas: el agua como componente único, la continuidad y/o permanencia del caudal, la estabilidad del cauce y el hecho de desembocar en otro río, mar o lago.

Otro concepto que configura la idea de río es el de caudal. Su variable cuantitativa diferencia al río del torrente o el arroyo:

"Los ríos son corrientes permanentes de agua que desembocan en el mar o en otros ríos o lagos [...] cuando el caudal es menor o son estacionales hablamos de arroyos o torrentes" (TX9.ESO1N, p.91)

Es frecuente relacionar las variaciones de caudal con las precipitaciones y con ello las estaciones lluviosas con caudales abundantes y las secas con caudales exiguos.

El binomio ciudad-río (categoría b), aparece en todas las editoriales y niveles de enseñanza revisados, tanto en educación primaria como en secundaria, con diferentes perspectivas, niveles de profundidad y rigor. Las relaciones de ciudad con

4 La codificación de los textos revisados indica TX9 ( $n^{\circ}$ de texto) ESO (educación secundaria) 1 (curso) $\mathrm{N}$ o $\mathrm{S}$ (naturales o sociales). 
Tabla 2. Unidades de información por áreas y niveles.

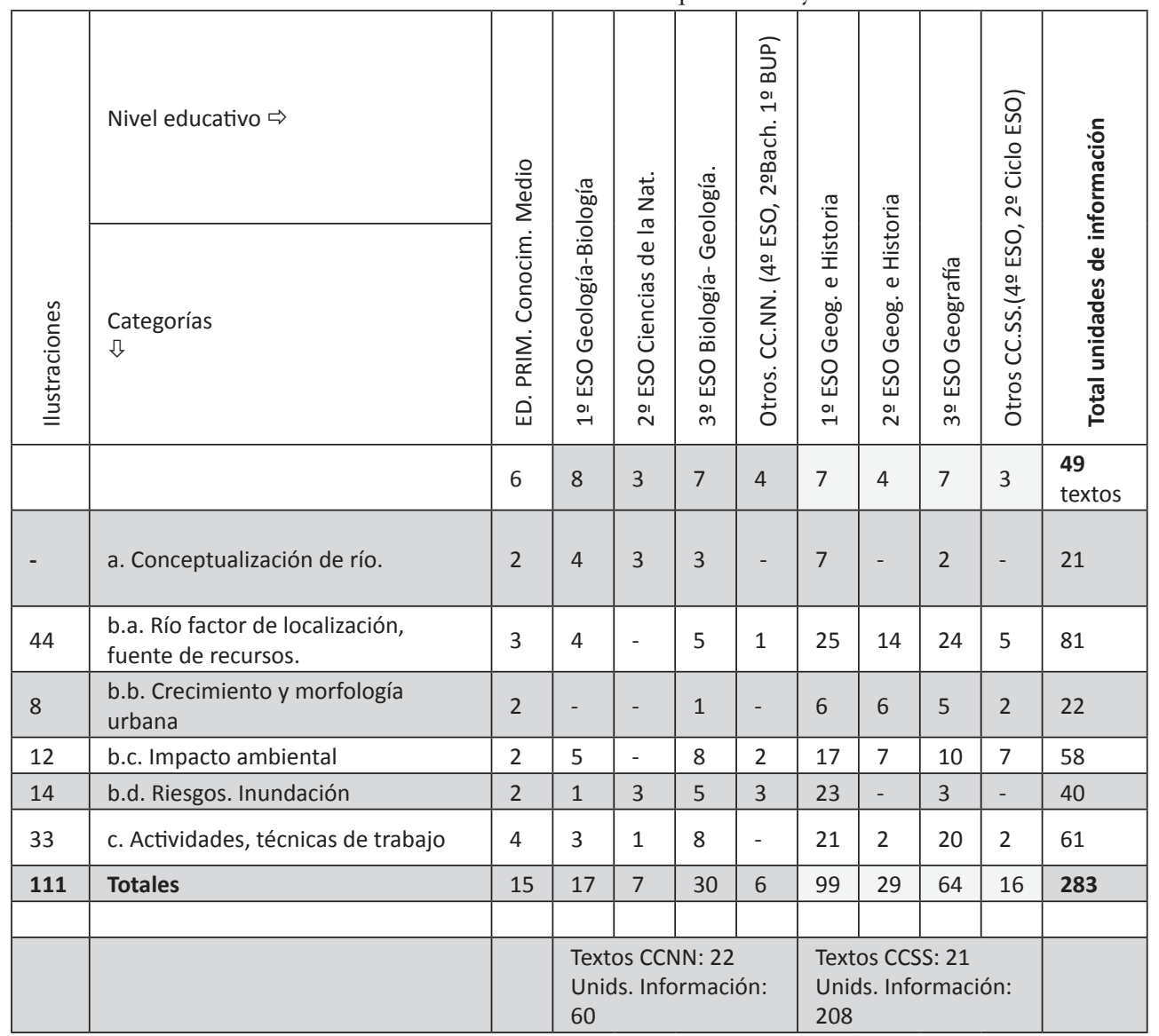

Elaboración propia

el río se establecen fundamentalmente en base a su capacidad de abastecimiento, defensa o vía de transporte, haciendo del río un factor determinante para el asentamiento de grupos humanos y desarrollo de ciudades. La importancia de esta relación aparece en los libros de texto de forma explícita en diferentes bloques de contenidos, ya sea en la diferenciación de paisajes rural y urbano, en la génesis de las primeras civilizaciones o en actividades prácticas sobre mapas y fotografías en las que se presenta una ciudad fluvial aunque a veces no se haga mención expresa a esta circunstancia. En esta categoría se agrupan la mayor parte de las unidades de contenido, un $71 \%$ del total.

El río como factor de localización urbana aparece en el tercer ciclo de educación primaria y en los primeros cursos de educación secundaria tanto en ciencias sociales como naturales. Los recursos hídricos y las características favorables de la llanura 
Revista de Humanidades, 37 (2019). p. 209-234. ISSN 1130-5029

fluvial se presentan como facilitadores de la vida humana en la mayoría de las unidades:

"Los ríos ofrecen posibilidades de vida y actividad económica (agua potable, regadios, navegación fluvial), por lo que la población se concentra en sus riberas" (TX33. ESO1S, p.121)

El apoyo de imágenes es aquí muy destacado con el $40 \%$ de todas las ilustraciones, incluyendo por igual a ciudades españolas como de otros países:

"Es el lugar concreto donde se instala la ciudad [...] origen como puente, junto a un río como París, Viena o Córdoba [...], como puerto en la desembocadura de un río para comunicar el interior con la costa como Londres, Lisboa, Bilbao..." [el texto se apoya con una imagen de Passau con el pie de foto: Passau (Alemania) en la confluencia del Danubio con el Inn y el Liz] (TX37.ESO2S, p.48).

La condición fluvial como factor de localización es argumento central e ineludible en las "primeras civilizaciones", Egipto y Mesopotamia. En algunas editoriales es también protagonista con el imperio romano, Al-Ándalus o en la creación de los burgos medievales y, más escasamente, en referencias de historia moderna o contemporánea. Se utilizan textos explícitos e ilustraciones que muestran escenas urbanas, ambientes domésticos o actividades económicas diversas con el río como lugar-escenario.

La evolución y transformación de la ciudad aparece bajo distintos epígrafes y títulos de subtemas, ya sea desde una perspectiva histórica o en relación con la explotación de los recursos y transformación del entorno, con los conceptos de cambio y evolución urbana como objetivos. Los textos se acompañan con frecuencia de fotografías o ilustraciones, a modo de secuencia de viñetas que muestran los cambios transcurridos en diferentes épocas. El impacto ambiental de la ciudad sobre los ríos aparece de forma explícita o implícita en la mayoría de los textos de todos los niveles educativos, con destacada presencia de ilustraciones, algunas de enorme interés, que constituyen un tercio de las unidades de contenido en las relaciones ciudad-río (categoría b.c.). Los problemas ambientales se plantean con frecuencia acompañados de soluciones técnicas: contaminación-depuración, escasez-embalses y trasvases, gasto en regadío-sistemas eficientes, inundación-defensas, siendo anecdóticas las soluciones integrales, el cuestionamiento del consumo, el control del crecimiento o la recuperación de espacios fluviales. El agua se presenta generalmente en clave de escasez y sequía: "Andalucía es una comunidad deficitaria en agua [...], por la escasez de precipitaciones, evaporación por altas temperaturas, contaminación y sobreexplotación de acuiferos" (TX8.ESO1N, p.118). Las soluciones se centran fundamentalmente en el ahorro doméstico y en la distribución, sin considerar la protección de ríos o acuíferos. 
¿Ayudan los libros de texto a comprender... - A.Guello Gijón y otros

Las crecidas de los ríos y las inundaciones aparecen en los cursos de $3^{\circ}$ y $5^{\circ}$ de la educación primaria en el área de Conocimiento de Medio, pero es en educación secundaria cuando las referencias son significativas, sobre todo en $1^{\circ}$ de Ciencias Sociales y también en Ciencias de la Tierra de bachillerato. La perspectiva mayoritaria es la geográfica, geológica y ambiental, fundamentalmente en relación con la hidrosfera, las aguas superficiales, el medio físico, las aguas en Europa, España, Andalucía, y el clima, siendo predominante la presencia en el apartado de riesgos catastróficos y riesgos climáticos, contraponiendo los episodios de precipitaciones y desbordamiento de los ríos, siempre trágicos y perversos, a los periodos de estiaje y sequías. Desde la perspectiva histórica se ofrece una visión benefactora al tratar el nacimiento de las grandes civilizaciones, contenido que aparece de forma reiterada en todos los textos de $1^{\circ}$ de ESO de Ciencias Sociales junto al concepto de ciudad fluvial. La perspectiva urbanística es menos importante aunque aparece en casi todos los niveles educativos.

Respecto a las actividades prácticas y propuestas de trabajo, se han tenido en cuenta solo aquellas que podrían incidir directa y específicamente en la adquisición de destrezas y procedimientos para el conocimiento de los ríos en el ámbito urbano. De esta categoría se ha extraído 61 unidades de información, el $25 \%$ del total, considerando la diversidad de planteamientos, la ubicación dentro de las unidades didácticas y el uso de ilustraciones. La mayoría corresponde a $1^{\circ}$ y $3^{\circ}$ de Ciencias Sociales.

\section{DISGUSIÓN}

Los ríos forman parte sustancial de los contenidos escolares en educación primaria y secundaria, básicamente desde perspectivas geográfica y geológica, tratando con detalle conceptos hidrográficos y geomorfológicos con apoyo de ilustraciones. Los ríos son presentados en su "espacio natural", como agentes geológicos, componentes del paisaje, portadores del recurso agua y objeto de explotación, organizadores de territorios agrarios y excepcionalmente como elementos del espacio urbano del que quedan excluidos. Salvo su protagonismo en los temas de "primeras civilizaciones", el río es ajeno a la ciudad, sin embargo siempre está presente el agua, su escasez, la necesidad para el abastecimiento, la justificación de infraestructuras como embalses y trasvases, pero sin que se establezcan claras relaciones entre el agua que se utiliza y el río. El agua es un recurso para uso urbano pero desvinculado del río, un agua ajena a sus fuentes.

\subsection{Conceptualización de río, caracterización y funciones}

La definición de río es reiterativa a lo largo del tránsito académico y típica pregunta de examen, por ello tiene un importante peso en la cultura escolar y en los 
Revista de Humanidades, 37 (2019). p. 209-234. ISSN 1130-5029

esquemas culturales de la ciudadanía. Las definiciones de río encontradas revelan escaso rigor científico, al no considerar el flujo de nutrientes, la fracción sólida o la evolución del cauce y mucho menos la desaparición por infiltración en formaciones carbonatadas o arenosas litorales. Estas simplificaciones son mantenidas tanto en ciencias naturales como en ciencias sociales a lo largo de los cursos y pueden incidir negativamente en la construcción de la idea de río (Ibarra, 2007; Peñas, 2011), minusvalorando o rechazando la presencia de elementos naturales en los cauces fluviales en la ciudad como cantos rodados, troncos, ramas y hojas. La idea de estabilidad dificulta igualmente la percepción adecuada de los eventuales cambios de caudal o los procesos morfodinámicos propios de los ríos. Es evidente la escasa actualización de los textos respecto de nuevos enfoques habidos en geografía o en hidrogeomorfología y especialmente en gestión hidráulica, aun en las ediciones más modernas de 2016. Por ello siguen siendo vigentes las apreciaciones de Parcerisa (1996, p.39): "los textos escolares no siempre recogen las últimas aportaciones hechas desde la ciencia y continúan repitiendo interpretaciones que ya se consideran obsoletas y superadas por la comunidad científica".

Los datos obtenidos destacan la relación entre las precipitaciones y el caudal de los ríos, vinculando estaciones lluviosas con ríos caudalosos y estaciones secas con caudales escasos. Sin embargo la realidad es otra, ya que la regulación, el aprovechamiento hidroeléctrico y, sobre todo, el regadío, invierten el régimen de caudales con alteración severa en el ecosistema fluvial, por lo que el caudal que vemos en la ciudad responde a la gestión del agua más que a las precipitaciones (Ollero, 2012). Los textos escolares soslayan esta importante cuestión, omitiendo información relevante e imprescindible para interpretar adecuadamente la realidad fluvial. Desde una perspectiva optimista tendríamos aquí una oportunidad para debatir en el aula los modelos de gestión del agua y los embalses, la influencia del regadío en el tramo fluvial urbano, el impacto de las hidroeléctricas, la regulación de los caudales ecológicos o la escasa consideración que se tiene con los ecosistemas fluviales.

Respecto a las ausencias cabe citar el modelo de río-rambla al no coincidir con la definición predominante, por lo que los escolares del este y sureste español tendrán dificultad en percibir y valorar su espacio fluvial. La ausencia de alusiones a la conectividad lateral y en profundidad, y con ello las relaciones del río con los acuíferos, impide valorar adecuadamente los encauzamientos y canalizaciones. La escasa referencia a la conectividad longitudinal lleva a desconectar el tramo urbano del resto del río, lo que dificulta asumir el impacto ambiental de la ciudad aguas abajo, la construcción del concepto "cuenca" o la necesaria coordinación interurbana para acometer acciones conjuntas. Es generalizada asimismo la ausencia de referencias al río como patrimonio cultural, etnográfico o natural (Estepa et al., 2011; Ibarra, 2007), no solo en unidades didácticas específicas sobre patrimonio que pueden suplirse con materiales didácticos complementarios (Gil y Gómez, 2014), sino también en contenidos de carácter económico, turístico o en alusiones al desarrollo sostenible, por el que apuestan las ciudades que han mejorado sus espacios fluviales. 
¿Ayudan los libros de texto a comprender... - A.Cuello Gijón y otros

\subsection{Relaciones del río con la ciudad}

El aprovechamiento económico del agua determina la relación ciudad-río, siendo anecdótico el lugar del que procede, sea río o acuífero (Ibarra, 2007). El río es fundamentalmente un recurso económico: agua, energía y en menor medida transporte (en España), estando ausentes los bienes y servicios ambientales o ecosistémicos (Bermúdez, 2016).

El papel del río como elemento estructurador del espacio urbano está ausente, a pesar de que el contexto del discurso sea idóneo para destacarlo; algunas referencias en este sentido: el río Zadorra está ausente en la morfología urbana de Vitoria (TX29.ESO1S) o no se hace mención al corredor del Guadalquivir en la expansión urbana en Andalucía (TX35.ESO1S), ni en el caso de un texto que describe la transformación de Córdoba a lo largo de su historia (TX36.ESO2S); en una unidad didáctica sobre paisajes rurales y urbanos españoles se obvian los paisajes fluviales (TX37.ESO2S), igual sucede al hablar de la "diversidad y señas de identidad de las ciudades españolas" donde no aparecen los ríos. La rehabilitación de ciudades y el desarrollo urbano en los siglos XX y XXI no considera las restauraciones fluviales urbanas de los últimos treinta años (TX45.ESO3S).

La evolución de la relación ciudad-río se presenta en los textos desde una doble perspectiva, una histórica, caracterizando el hecho urbano en sucesivas épocas, y otra, geográfica, como proceso de transformación del paisaje, con protagonismo de la ilustración en ambos casos. En contraste con la profusa descripción de los cambios morfológicos, arquitectura, medios de vida, economía, explotación de recursos, etc. de la ciudad, los comentarios sobre los cambios en el entorno fluvial son mínimos aun siendo evidentes en las ilustraciones. Así, los encauzamientos, soterramientos o desplazamientos del cauce fuera de la ciudad, tan frecuentes en las poblaciones fluviales españolas (Pellicer y Ollero, 2004), están ausentes en los contenidos escolares sobre los procesos de transformación urbana. Similar trato tienen las vías de comunicación trazadas en los valles fluviales que causan un importante impacto ambiental además de limitar el acceso desde las ciudades.

Frente a la sequía pertinaz y el desequilibrio hídrico se apela constantemente a los embalses y trasvases como solución, ignorándolos al tratar el impacto ambiental de las ciudades, de la agricultura o el impacto del "hombre" sobre el medio. Las obras hidráulicas aparecen en ilustraciones y mapas como si se tratara de un elemento natural más del territorio, enla mayoría de los textos se tratan comoactuaciones intrínsecamente buenas sin más reflexión a la hora de tratar el "problema de agua" o "la escasez".

"El ser humano ha construido muchos embalses y canales para utilizar el agua [...] los embalses se emplean para riego y abastecimiento de pueblos y ciudades... o para regular crecidas y evitar inundaciones, también para producir energía eléctrica. [...] en España el abastecimiento de agua ha sido siempre un problema y se ha intentado solucionar con grandes trasvases. [...] El PHN pretende utilizar el agua de los ríos 
Revista de Humanidades, 37 (2019). p. 209-234. ISSN 1130-5029

del norte para paliar la escasez que hay en el sur donde el crecimiento urbano y el aumento de regadios ha disparado el consumo" (TX49.ESO4S. p.40).

Se refuerza la idea de corregir los "déficits estructurales, llevando agua de las cuencas a las que les sobra agua y que sin aprovechar tiran al mar, a las cuencas deficitarias que padecen sed", reduciendo así la gestión a una simple cuestión de "fontanería hidráulica" (Antoranz, 2003, p.386) gobernada por la presión de la demanda. Es necesario plantear a los alumnos las contradicciones del discurso de escasez, sequía y desequilibrio, apoyado con frecuencia de imágenes angustiosas, con el caudal extraordinario que suelen llevar los ríos en verano para el riego de campos de algodón y maíz o las numerosas urbanizaciones con piscinas y césped.

Es notoria la escasa presencia de las agresiones urbanísticas a los ríos, la ocupación del territorio fluvial, la segunda residencia o el aumento constante de la demanda de la agricultura, así como la ausencia de crítica a los modelos de desarrollo, de ciudad o del modelo económico. Serían deseables más soluciones como "[...] limitar los asentamientos urbanos en zonas deficitarias de agua" (TX22.ESO3N), o análisis del tipo "España es un país con un elevado consumo de agua [...] España gasta tanta agua como Alemania que casi duplica nuestra población. El consumo urbano y las actividades de ocio agravan la situación como es el caso de las nuevas urbanizaciones y los campos de golf en la costa mediterránea" (TX42.ESO3S, p.196). En esta línea, parece intencionado atribuir responsabilidades a la ciudadanía y reclamar un buen uso doméstico como medida, a veces la única, de ahorro y buena gestión. Sin embargo el consumo doméstico supone sólo un 12\% y sigue reduciéndose en los últimos años, mientras el agrícola es un $82 \%$ y aumenta permanentemente.

Las referencias obtenidas de los textos evidencian de manera mayoritaria juicios y opiniones sobre las inundaciones que, lejos de las posturas de la geografía y el urbanismo actuales, alimentan concepciones cargadas de aversión construidas desde una visión antropocéntrica del funcionamiento de los ríos, realzando la visión catastrofista y perniciosa sobre propiedades, personas y la actividad económica. Solo en el marco de las primeras civilizaciones (Egipto o Mesopotamia) las inundaciones son beneficiosas para el desarrollo de la ciudad. En textos de reciente publicación aparecen unidades de información que se refieren a las crecidas e inundaciones como episodios de la dinámica natural, con mención a los conceptos de llanura de inundación y exposición al riesgo, así como medidas de planificación urbanística y ordenación urbana. Sin embargo no hay referencias a los sistemas y redes de alerta ni a la capacidad de previsión y gestión de las crecidas. Los datos recogidos señalan a las precipitaciones como causa única y directa de las inundaciones, sin abordar otras cuestiones como la ocupación del espacio fluvial por la ciudad, la disminución de la infiltración o las canalizaciones; tampoco se trata la falta de libertad del río por motas, muros o bóvedas. Las soluciones basadas en la restauración fluvial, recuperación de espacios fluviales u otras medidas urbanísticas son anecdóticas, prevaleciendo las de carácter hidráulico y estructural. 
¿Ayudan los libros de texto a comprender... - A.Cuello Gijón y otros

El tratamiento de las inundaciones en los textos escolares también contribuye a construir la idea de río, sus funciones, necesidades y las relaciones con la ciudad, por ello es muy importante la valoración que se dé a estos eventos y cómo se presenten al alumnado. Es muy probable que el contacto más directo y consciente de la población que vive en una ciudad fluvial con su río sea a través de una crecida, dándose la oportunidad de tomar conciencia de su existencia, de su vitalidad, su fuerza y su capacidad para modificar el entorno. Los datos obtenidos para esta categoría (b.d.) no ayudan a interpretar las crecidas desde la complejidad ni a analizar críticamente el hecho fluvial en relación con la ciudad, lo que dificulta la consideración de medidas de carácter integral, de ordenación de territorio y participación ciudadana, restauración de los espacios fluviales, etc.

Sobre estas importantes cuestiones, la Unión Europea ha aprobado dos directivas fundamentales: Marco del Agua (2000/60/CE) y sobre Riesgo de Inundaciones (2007/60/CE), pero no aparecen en ningún texto aunque sí se trata el papel de la UE en otros ámbitos (Ladrera, 2016). Asimismo destaca la exigua presencia de los Planes Hidrológicos como instrumentos de planificación y las Cuencas Hidrográficas como unidad geográfica de gestión.

Los resultados ponen de manifiesto el protagonismo de las ilustraciones en el tratamiento de los ríos y sus relaciones con la ciudad, tanto en lo cuantitativo como en lo cualitativo, con calidad gráfica aceptable y elevado potencial didáctico, sin embargo su aprovechamiento es escaso y aparecen con frecuencia desconectadas de los textos donde se insertan (Braga y Belver, 2016; Occelli, 2013). Esta situación es notoria en las unidades didácticas sobre transformación del paisaje, incidencia del funcionamiento urbano en el territorio o evolución histórica de la ciudad, donde numerosas ilustraciones de contextos urbano-fluviales quedan huérfanas de discurso que las rentabilice, perdiéndose excelentes oportunidades para el análisis de la realidad fluvial de la ciudad en base a estas imágenes ya que el profesorado sigue mayoritariamente las indicaciones del texto así como las actividades que este propone (Cañal et al., 2016).

\subsection{Actividades y técnicas de trabajo}

El interés por las actividades prácticas en los libros de texto es escaso (García y Martínez, 2003), lo que resulta paradójico en las enseñanzas del medio ambiente ya que es una de sus características principales (Cintas, 2000; Mateos, 2008). En la muestra revisada predominan los ejercicios de repaso con solución en el texto, frente a las actividades abiertas, de taller, laboratorio o de campo, y cuando estas existen están dirigidas a ámbitos fluviales naturales o rurales, generalmente protegidos (Cuello, 2010). La presencia de actividades sobre aspectos ambientales de los ríos en la ciudad es insignificante, exceptuando los ejercicios tradicionales sobre mapas, análisis de prensa o interpretación de imágenes que utilizan un contexto urbano para su desarrollo. La información necesaria para realizar las actividades está 
mayoritariamente en el propio texto y, en menor medida, en la red, en detrimento de la obtenida mediante salidas al entorno, cada vez más escasas y para las que el profesorado tiene pocas referencias metodológicas, reduciéndose enormemente el abanico de actividades atractivas para el alumnado.

El discurso de la mayoría de las actividades refuerza las posiciones del texto, sobre todo cuando son posibles diferentes enfoques, sin ofrecer alternativas o divergencias, predominando los aspectos descriptivos sobre los valorativos, analíticos o discusivos. Los enunciados fijan la situación de partida sin que esta forme parte de la discusión: "se quiere construir un pueblo turístico [...] busca opciones para el suministro de agua" (TX35.ESO1S); o plantea la valoración de un trasvase de agua después de destacar el desequilibrio entre cuencas y el concepto de aguas sobrantes (TX42.ESO3S).

La mayoría de las editoriales incluyen al final de la unidad didáctica un apartado de actividades complementarias, trabajos prácticos, experimentos, etc., con denominaciones como taller de geografía, desarrolla tus competencias o para saber más. Estas propuestas suelen ser mucho más interesantes y útiles que las incluidas en el texto de la unidad, de manera que la mayoría de las actividades registradas que pudieran contribuir al mejor conocimiento de la realidad fluvial de la ciudad se localizan en estos apartados; ejemplos de ello son una actividad que propone el debate sobre la construcción de embalses (TX45.ESO3S), otra sobre participación ciudadana en el planeamiento urbano a través del análisis de prensa (TX29.ESO1S), o el muestreo e identificación de macroinvertebrados a partir de una salida urbana (TX18.ESO3N). En cualquier caso, el profesorado confiesa no tener tiempo para este tipo de propuestas al dar prioridad al texto informativo de la unidad y sus ejercicios, ya que prima el aprendizaje de conceptos sobre procedimientos o valores (Hernández, 2015), aunque en la mayoría de los casos se trate de informaciones de bajo nivel de elaboración conceptual.

\section{GONCLUSIONES}

Una visión general y secuenciada de los textos revisados en este estudio ofrece un mosaico multifocal del río de difícil integración. Se podría decir que hay un río geológico, básicamente erosivo, que participa en un ciclo que talla la tierra y conforma paisajes. Un río geográfico que forma parte del ciclo del agua a modo de contenedor aislado, como pieza de un dibujo standard que intenta explicar un proceso complejo y que con frecuencia encierra errores conceptuales relevantes; es una línea azul en los mapas, sinuosa, interrumpida por presas, acompañada de términos como vertiente, cauce, meandro, delta, etc., y navegable en Europa. Un río riesgo natural, agresivo, que se desborda generando catástrofes como consecuencia de un clima caprichoso y al que hay que someter con obras de infraestructura. Un río ecosistema con seres vivos a los que hay que cuidar solo en los espacios protegidos. Un río histórico 
¿Ayudan los libros de texto a comprender... - A.Cuello Gijón y otros

que siglos atrás favoreció el desarrollo de civilizaciones exóticas. Pero sobre todo los textos resaltan un río económico, portador de un recurso natural escaso, mal repartido y disputado (Antoranz, 2006), que riega cultivos y mueve turbinas y por tanto crea riqueza, desarrollo, crecimiento, y que no debe desperdiciarse tirándolo al mar; la construcción de infraestructuras asegura que el recurso se distribuya y satisfaga todas las demandas en constante crecimiento.

Esta fragmentación conceptual y discursiva supone un obstáculo para la construcción de un esquema de ideas coherente y complejo sobre el río, generando por el contrario un puzle heterogéneo sin orden interno con el que es imposible interpretar la realidad fluvial en su globalidad.

La información existente en los textos sobre el funcionamiento del sistema fluvial, sus relaciones con la ciudad, aspectos como la sequía o inundaciones, las medidas y los modelos alternativos de gestión hidrológica, etc., es insuficiente, poco rigurosa y sesgada (Herrera, 2007), a pesar del cambio de paradigma acaecido en el último cuarto de siglo. En este sentido, los libros de texto deberían mejorar sustancialmente el tratamiento de las cuestiones relativas al agua y los ríos, facilitando la construcción de esquemas de conocimiento más útiles y con mejor armazón tecnocientífico para comprender los problemas actuales (Ibarra, 2007) y contrarrestar los valores establecidos (Bonotto, 2010). A pesar de encontrar aspectos positivos en algunos de los textos revisados, es evidente su escasa actualización para contribuir a la mejora del aprendizaje de cuestiones ambientales, siendo necesario incorporar nuevas perspectivas procedentes tanto del ámbito social como del académico y técnico. Es incomprensible la invisibilidad del hecho fluvial en la ciudad cuando la realidad es la contraria, obviando los problemas que esta plantea y excluyendo a la ciudadanía de las competencias necesarias para afrontarlos. Es inaceptable la ausencia de las directivas europeas que determinan las nuevas orientaciones en temas de agua, o que pasen desapercibidas las intervenciones en la mejora de los espacios fluviales urbanos que se vienen realizando en España en los últimos cuarenta años, o que se omita la actividad de los movimientos sociales y académicos en favor de la recuperación de los ríos y el desarrollo de una nueva cultura del agua.

En definitiva, según los datos manejados en este estudio, los libros de texto de educación secundarianofacilitan laconstruccióndeunmodelointerpretativodelríoenel contextourbano, estánlejosdeofrecerlosmediosnecesariosparapodertomarconciencia de la realidad fluvial de la ciudad, debiendo hacer una reformulación y actualización de sus contenidos y contribuir así a un mejor conocimiento de los ríos en la ciudad.

\section{BIBLIOGRAFÍA}

ANELE (2018). El Libro educativo en España, curso 2017-2018. Madrid: Asociación Nacional de Editores de Libros y material de enseñanza. Disponible en: https:// anele.org/sala-de-prensa/informes/ (última consulta 14.07.2018). 
Revista de Humanidades, 37 (2019).p. 209-234. ISSN 1130-5029

Antoranz, Antonia y Martínez, Javier (2003). El agua y el sistema educativo español. En Del Moral, Leandro; Arrojo, Pedro (Coord.), La directiva marco del agua: realidades y futuros, (pp. 385-424). Zaragoza: Fundación Nueva Cultura del Agua.

Arrojo, Pedro (2008). La nueva cultura del agua del siglo XXI. Sociedad Estatal Zaragoza: Expoagua 2008. Disponible en: https://www.zaragoza.es/contenidos/ medioambiente/cajaAzul/palabras/Arrojo_ES.pdf (última consulta 12.10.2018).

Atienza, Encarna y Van Dijk, Teun (2010). Identidad social e ideología en libros de texto españoles de ciencias sociales. Revista de Educación, 353, 67-106. Disponible en: https://repositori.upf.edu/handle/10230/23844 (última consulta 12.10.2018).

Bermúdez, Gonzalo; De Longhi, Ana y Gavidia, Valentín (2016). El tratamiento de los bienes y servicios que aporta la biodiversidad en manuales de la educación secundaria española: un estudio epistemológico. Revista Eureka sobre Enseñanza y Divulgación de las Ciencias, 13(3), 527-543. Disponible en: http://hdl.handle. net/10498/18495 (última consulta 12.10.2018).

Bernardo, José y Calderero, José (2000). Aprendo a investigar en educación. Madrid: Rialp.

Bisquerra, Rafael (Coord.) (2009). Metodología de la investigación educativa. Madrid: La Muralla, $2^{\mathrm{a}}$ ed.

Bonotto, Dalva y Semprebone, Angela (2010). Educação ambiental e educação em valores em livros didáticos de ciências naturais. Ciência y Educação (Bauru), 16(1) 131148. Disponible en: http://www.scielo.br/scielo.php?script=sci_arttext\&pid=S151673132010000100008\&lng=es\&nrm=iso\&tlng=pt (última consulta 25.11.2018).

Braga, Gloria y Belver, José (2016). El análisis de libros de texto: una estrategia metodológica en la formación de los profesionales de la educación. Revista Complutense de Educación, 27(1), 199-218. Disponible en: https://revistas.ucm.es/ index.php/RCED/article/view/45688 (última consulta 25.11.2018).

Cañal, Pedro et al (coord.) (2016). La enseñanza sobre el medio natural y social. Investigaciones y experiencias. Sevilla: Díada.

Cardak, O. (2009). Science students' misconceptions of the water cycle according to their drawings. Journal of Applied Sciences, 9(5), pp. 865-873. Disponible en https:// scialert.net/fulltextmobile/?doi=jas.2009.865.873 (última consulta 15.04.2019)

Chevallard, Yves (1985). La transposition didactique. Du savoir savant au savoir enseigné. Grenoble: La Pensée Sauvage.

Cintas, Rosa (2000). Actividades de enseñanza y libros de texto. Investigación en la Escuela, 40, 97-106. Sevilla: Díada.

Cuello, Agustín (2010). Los tramos fluviales urbanos como ámbitos de aprendizaje. Una valoración de su potencial educativo y los obstáculos que plantea su utilización. En Junyent Pubill, Mercè y Cano Muñoz, Luis (Coord.), Investigar para avanzar en educación ambiental (p. 63-84). Madrid: Organismo Autónomo Parques Nacionales. Ministerio de Medio Ambiente y Medio Rural y Marino. 
¿Ayudan los libros de texto a comprender... - A.Cuello Gijón y otros

Cuello, Agustín (2018). Las inundaciones del invierno 2009-2010 en la prensa, un recurso educativo para las ciencias sociales. Revista de Investigación en Didáctica de las Ciencias Sociales REIDICS, 2, 70-87. Disponible en: https://mascvuex.unex. es/revistas/index.php/reidics/article/view/3039 (última consulta 18.10.2017).

Estepa,Jesús etal.(2011).Análisis del patrimonio presente en los libros de texto: obstáculos, dificultades y propuestas. Revista de Educación, 355, 573-588. Disponible en: https://www.mecd.gob.es/revista-de-educacion/numeros-revista-educacion / numeros-anteriores/2011/re355/re355_24.html (última consulta 06.07.2018).

Fernández, Pilar y Caballero, Presentación (2017). El libro de texto como objeto de estudio y recurso didáctico para el aprendizaje: fortalezas y debilidades. Revista Electrónica Interuniversitaria de Formación del Profesorado, 20(1), 201-217. Disponible en: http://dx.doi.org/10.6018/reifop.20.1.229641 (última consulta 21.07.2018).

Franquesa, Teresa (2017). Sobre educación ambiental urbana. Una visión desde Barcelona. En Diputació de Barcelona (Ed.), Educació ambiental. D'on venim? Cap a on anem? (pp. 65-85). Barcelona: Diputació de Barcelona.

García, Susana y Martínez, Cristina (2003). Análisis del trabajo práctico en textos escolares de primaria y secundaria. Enseñanza de las ciencias, número extra, 5-16.

García Pérez, Francisco F. (2011). Geografía, problemas sociales y conocimiento escolar. Anekumene. Revista virtual. Geografia, cultura y educación, 1(2), 6-21. Disponible en: http://www.anekumene.com/index.php/revista/article/view/24/23 (última consulta 21.07.2018).

García Pérez, Francisco F. (2014). Ciudadanía participativa y trabajo en torno a problemas sociales y ambientales. En Pagés, Joan y Santisteban, Antoni, Una mirada al pasado y un proyecto de futuro: investigación e innovación en didáctica de las ciencias sociales (vol. 1, p. 119-126). Barcelona: Universitat Autònoma de Barcelona.

García Pérez, Francisco F. (2015). Educar en la escuela para afrontar los problemas del mundo. En VV. AA., Más allá de los posible. La dimensión política de los derechos humanos en el siglo XXI (pp. 145-172). Tafalla: Txalaparta.

Gil Meseguer, E.; Gómez Espín, J.Mª (2014): La senda del agua. Itinerarios didácticos para la enseñanza activa de la Geografía en educación Primaria, Secundaria y Universidad. En Martínez, R. y Tonda-Monllor, E. Nuevas perspectivas conceptuales y metodológicas para la Educación Geográfica. Tomo II pp. 219-228 Universidad de Córdoba. Grupo de Didáctica de la AGE.

Worldwatch Institute (ed.) (2016). Ciudades sostenibles. Del sueño a la acción. Barcelona: FUHEM - Icaria.

Henry King, Chris (2010). An analysis of misconceptions in science textbooks: Earth science in England and Wales. International Journal of Science Education, 32(5), 565-601. 
Revista de Humanidades, 37 (2019). p. 209-234. ISSN 1130-5029

Hernández, Ana $\mathrm{M}^{\mathrm{a}}$ et al. (2015). Valores y enfoques ambientales de la enseñanza secundaria obligatoria a través de los libros de texto. Alcalá de Henares: Cátedra de Ética Ambiental FTPGB-UAH.

Herrera, Yayo (2007). El currículum oculto antiecológico de los libros de texto. Ambienta, $69,33-40$

Ibarra, Julia (2007). Nuevos contenidos educativos sobre el agua y los ríos desde una perspectiva CTS. Revista Electrónica de Enseñanza de las Ciencias, 6(3), 714728. Disponible en: http://reec.uvigo.es/volumenes/volumen6/ART13_Vol6_N3.pdf (última consulta 21.03.2017).

Ladrera, Rubén y Prat, Narcís (2016). Las políticas europeas y el consenso científico en materia de gestión y conservación de aguas no llegan a la escuela. En Fundación Nueva Cultura del Agua (ed.), IX Congrés Ibèric de Gestió i Planificació de l'Aigua (pp. 637-648). Valencia: Universidad de Valencia.

Link-Pérez, Melanie et al. (2010). What's in a Name: Differential labelling of plant and animal photographs in two nationally syndicated elementary science textbook series. International Journal of Science Education, 32(9), 1227-1242.

Marcén, Carmelo y Cuadrat, José $M^{\mathrm{a}}$ (2012). Argumentos educativos para enseñaraprender el agua en enseñanza obligatoria. Serie Geográfica, 18, 65-75. Disponible en: http://hdl.handle.net/10017/13361 (última consulta 14.04.2018).

Martínez Bonafé, Jaume (2008). Los libros de texto como práctica discursiva. RASE. Revista de la Asociación de Sociología de la Educación, 1(1), 62-73.

Martínez Gil, Javier (2008). Una Nueva Cultura del Agua en un mundo en crisis. . Jornadas "El agua derecho humano y raíz de conflictos" (pp. 549-564). Zaragoza: Fundación Seminario de Investigación para la Paz.

Martínez, Jaume y Rodríguez, Jesús (2010). El currículum y el libro de texto. Una dialéctica siempre abierta. En Gimeno, José, Saberes e incertidumbres sobre el currículum (pp. 246-269). Madrid: Morata.

Moreno-Fernández, Olga (2015). Problemáticas socioambientales desde un enfoque de ciudadanía planetaria en las aulas. Revista de Humanidades, 24, 169-192.

Occelli, Maricel y Valeiras, Nora (2013). Science Textbooks as Research Objects: A Bibliographic Review. Enseñanza de las Ciencias, 31(2), 133-152.

Ollero, Alfredo (2012). Territorios fluviales sostenibles. Documento de presentación ppt. En Iraungarritasunari buruzko III. Campus de Álava, 27 y 28 de marzo. Universidad del País Vasco. Disponible en: http://docplayer.es/39774157Territorios-fluviales-sostenibles.html (última consulta 13.07.2017).

Parcerisa, Artur (1996). Materiales curriculares. Cómo elaborarlos, seleccionarlos y usarlos. Barcelona: Graó.

Pellicer, Francisco y Ollero, Alfredo (2004). EL agua y la ciudad. Uno de los principales retos de la humanidad en el siglo XXI. Boletín de la A. G.E, 37, 3-13. 
¿Ayudan los libros de texto a comprender... - A.Cuello Gijón y otros

Peñas, Víctor y Masip, Inés (2011). ¡Destejiendo tópicos del agua! Vitòria-Gasteiz: Fundación Tomás y Valiente.

Reyero, Carmen et al. (2007). Las ilustraciones del ciclo del agua en los textos de Educación Primaria. Enseñanza de las Ciencias de la Tierra, 15(3), 287-294.

Tidball, K. G., y Krasny, M. E. (2010). Urban environmental education from a socialecological perspective: Conceptual framework for civic ecology education. Cities and the Environment (CATE), 3(1), art.11

Travé, Gabriel y Pozuelos, Francisco (2008). Consideraciones didácticas acerca de las líneas de investigación en materiales curriculares. A modo de presentación. Investigación en la Escuela, 65, 3-10.

Vasilachis, Irene (2006). La investigación cualitativa. En Vasilachis, Irene (Coord.), Estrategias de investigación cualitativa (pp. 23-64). Barcelona: Gedisa. 